\title{
АНАЛИЗ КОНСТИТУЦИОННО-ПРАВОВЫХ ОСНОВ ПРАВА ГРАЖДАН НА ДОСТУП К ИНФОРМАЦИИ О ДЕЯТЕЛЬНОСТИ ОРГАНОВ ГОСУДАРСТВЕННОЙ ВЛАСТИ В СОЕДИНЕННЫХ ШТАТАХ АМЕРИКИ
}

В современном мире большое значение имеет правовая возможность для населения получать информацию о деятельности органов государственной власти. Соответствующее законодательство имеется во всех демократических странах мира. Исходные положения о праве человека и гражданина на доступ к информации о деятельности органов государственной власти содержатся в конституциях стран мира, либо актах конституционного законодательства. В Соединенных Штатах Америки, как в государстве с самой старой писанной конституций, имеются свои уникальные особенности правового регулирования доступа граждан к информации о деятельности публичной администрации. Несмотря исходную правовую норму конституции о свободе слова, рассматривать права на доступ к информации в США необходимо в тесной связи с правом на об- ращение с петициями к органам государственной власти. Это подтверждается анализом действующего конституционного законодательства, нормы которого направлены на установление и гарантирование, а также создание механизма реализации права на доступ к информации о деятельности органов государственной власти. Население США имеет широкие возможности требовать получения и получать информацию от органов власти. При этом, как и в других государствах, в США существует законодательно установленный перечень оснований, по которым заявителям может быть отказано в предоставлении информации.

Ключевые слова: США, правительство в солнечном свете, информация, права и свободы, право на доступ к информации, информационные права, право на информацию в зарубежных странах.

\section{M. Tazieva}

\section{ANALYSIS OF CONSTITUTIONAL AND LEGAL FOUNDATIONS OF THE} RIGHT OF CITIZENS TO ACCESS THE INFORMATION ON THE ACTIVITIES OF PUBLIC AUTHORITIES IN THE UNITED STATES OF AMERICA

Nowadays the legal opportunity for the public to receive information on the activities of public authorities is of great importance. Appropriate legislation exists in all democratic countries of the world. The initial provisions on the human and citizen's right to access information on the activities of public authorities are contained in the constitutions of the countries of the world, or acts of constitutional legislation. In the United States of America, as in the state with the oldest written constitutions, there are unique features of the legal regulation of citizens' access to information on the activities of the public administration. Despite the basic legal norm of the constitution on freedom of speech, it is necessary to consider the rights to get access to information in the US in close connection

Опыт правового регулирования разнообразных общественных отношений в зарубежных странах (например, закрепления и регламен- with the right to petition government authorities. This is confirmed by the analysis of the current constitutional legislation, the norms of which are aimed at establishing and guaranteeing, as well as creating the mechanism for exercising the right to access information on the activities of public authorities. The US population has many opportunities to demand and receive information from authorities. At the same time, as in other states, the US has a legally established a list of grounds on which applicants may be denied information.

Key words: the USA, government in the sunlight, information, rights and freedoms, right to access to information, information rights, right to information in foreign countries.

тации права на информацию), произведенное на основе его исследования выводы, будут крайне полезны в сфрере правового регулиро- 
вания аналогичных общественных отношений в Российской Федерации, совершенствовании отечественной юридической практики.

Взвешенное и критическое отношение к заимствованным из-за рубежа способам и методам правового регулирования общественных отношений может способствовать улучшению российских практик, выработке новых правовых моделей, а возможно и отказу от западных идей.

Известных зарубежный исследователь М. Ансель в своем труде «Методологические проблемы сравнительного права» писал, что для тех, кто стремится изучать зарубежное право непременно откроются новые горизонты, юрист сможет не только лучше узнать национальное право своей страны, но и узнать специфические черты права стран зарубежных, сравнить право своей страны и зарубежных государств. «Сравнение способно вооружить юриста идеями и аргументами, которые нельзя получить даже при очень хорошем знании только собственного права» [2].

Гарантированное Конституцией Российской Федерации от 12 декабря 1993 г. право на информацию многогранно по своему содержанию и имеет различные аспекты, подвергавшиеся изучению отечественными учеными-конституционалистами.

Учитывая тот фракт, что Конституция России относится к конституционным актам мирового уровня и как со знанием дела отмечает В. Д. Зорькин «полностью соответствует лучшим мировым образцам» [8, с. 12], необходимо обратить внимание на то, каким образом право на информацию вообще и право на доступ к информации о деятельности органов государственной власти закреплено и регламентировано в конституционных актах некоторых зарубежных стран.

В частности, Основной закон нашего государства в части закрепления права на информацию полностью соответствует международным правовым актам.

В ст. 19 Всеобщей декларации прав человека и гражданина от 11 декабря 1948 г. говорится о том, что «Каждый человек имеет право на свободу убеждений и на свободное выражение их; это право включает свободу беспрепятственно придерживаться своих убеждений и свободу искать, получать и распространять информацию и идеи любыми средствами и независимо от государственных границ» [5].

В ч. 1 ст. 10 Конвенции о защите прав человека и основных свобод от 4 ноября 1950 г. сказано, что «Каждый имеет право свободно выражать свое мнение. Это право включает свободу придерживаться своего мнения и свободу получать и распространять информацию и идеи без какого-либо вмешательства со стороны публичных властей и независимо от государственных границ» [10].

Необходимыми условиями функционирования правового государства в современном мире является информационная открытость органов публичной власти, возможность для граждан получать информацию об их деятельности, получать без препятствий и без промедления общественно значимую информацию. Реализуя свое право на доступ к информации, граждане принимают реальное участие в управлении делами государства, могут контролировать деятельность государственных органов и их должностных лиц.

Право на доступ к инфрормации имеет сложную структуру и играет роль связующего элемента между личными, политическими и культурными правами человека. Только при условии его соблюдения можно говорить о фактической реализации личных, политических, социальных, экономических, экологических и культурных прав и свобод.

Указанные выше положения относительно права человека и гражданина нашли свое отражение в конституционных актах зарубежных государств. Соответственно, соблюдение со стороны государства гарантий реализации права на информацию делает возможным реализацию ряда прав человека, в особенности политических.

В подавляющем большинстве стран мира важнейшим и основным источником конституционного (государственного) права является конституция. Конституция имеет большую среди других правовых актов государства силу и находится на вершине их иерархии. Соответственно, нормы права, содержащиеся во всех других нормативно-правовых актах, не должны противоречить конституционным нормам, в противном случае они могут быть применены.

В конституции и актах, так называемого конституционного законодательства, содержатся важнейшие положения, регламентирующие организацию государственной власти и управления, реализацию прав и свобод человека.

Конституционное законодательство можно понимать в широком и узком смысле в зависимости от круга его источников.

Применительно к России в широком смысле оно включает в себя не только федеральные законы и законы субъектов Российской Федерации, но и иные нормативные правовые акты. 
Важно, чтобы такие акты были направление на регулирование основ конституционного строя, правового положения человека и гражданина, федеративного устройства, организации и функционирования органов государственной власти и органов местного самоуправления [3, с. $276 ; 4$, с. $70 ; 13$, с. $223-224]$.

В рамках настоящей статьи мы проанализируем конституционное законодательство Coединенных Штатов Америки. Конституционное законодательство США состоит, соответственно, из Конституции США, Билля о правах, федеральных законов, законов штатов.

Конституция Соединенных Штатов Америки, принятая в 1787 г, по праву считается самой старой из писанных конституций в мире, а также, из-за используемой в ней юридической техники, одной из самых незавершенных и расплывчатых. «В Конституции отсутствуют положения о важнейших институтах политической и государственной власти - о конституционном контроле, политических партиях, исполнительном аппарате, местном управлении...» [11]. Возможно по этой причине в США велика роль судебного прецедента.

В Конституции Соединенных Штатов прослеживается и довольно нечеткий подход к закреплению, регламентации и классифрикации конституционных прав и свобод человека и гражданина, и эта одна из причин по которой в ее тексте нет права на информацию в том виде, в каком мы его понимаем.

Между тем, в ней (точнее в Билле о правах от 1791 г.) есть базовые конституционные права и свободы, на основе которых можно вести речь о праве на информацию. Это свобода слова и свобода печати, а также прав на обращение с петициями к правительству.

23 июня 1980 г. Верховный Суд Соединенных Штатов Америки [14] рассматривая в заседании Первую поправку к Конституции США, которая закрепляет, что Конгресс не должен издавать законов (...) ограничивающих свободу слова или печати или право народа (...) обращаться к Правительству с петициями об удовлетворении жалоб», постановил: основное предназначение поправки «гарантировать свободу обмена информацией по вопросам, имеющим отношение к функционированию властей» [12, с. 37].

Создав прецедент Верховный Суд США отчасти способствовал появлению специального законодательства, регулирующего предоставление органами государственной власти физическим и юридическим лицам, обеспечивающего открытость и прозрачность их деятельности.
Как отмечает Е. В. Тарибо, «большое распространение в США получило понятие «судебная доктрина» (judicial doctrine), что означает принцип, лежащий в основе выводов, принятых в судебной практике» [16].

Можно сказать, что судебная доктрина, основанная на силе судебного прецедента, применяется для регулирования отношений во всех областях общественной жизни современных Соединенных Штатов Америки.

Как по этому поводу пишет О. Жидков, «среди судебных доктрин, выработанных Верховным Судом США, выделяются специальные судебно-конституционные доктрины, представляющие собой своеобразные комбинации конституционного текста с серией судебных решений; судебно-конституционные доктрины вырастают из конкретных и казуистических решений благодаря принципу судебного прецедента» [6, с. 105-105].

Судебные доктрины стран мира характеризуются следующими основными чертами: 1) источником судебной доктрины будет являться судебная практика; 2) судебные доктрины носят нормативный характер и фрормируются на основе судебного прецедента (совокупности однотипных судебных решений по однотипным делам); 3) соответственно, сформировавшаяся судебная доктрина служит способом разрешения однотипных судебных дел [16].

Впрочем, регулирование общественных отношений при помощи судебной доктрины характерно не только для США, но и для ряда стран Западной Европы.

Отметим, что еще до указанного выше решения Верховного Суда США были приняты законы, направленные на регулирование информационной открытости органов власти. Эти законы получили название «законы солнечного света» («sunshine laws») [1].

В США к одному из базовых федеральных законов из числа «законов солнечного света», регулирующих отношения, возникающие по поводу предоставления третьим лицам информации, касающейся деятельности органов государственной власти, можно отнести Акт о свободе информации (The Freedom of Information Act [7]), принятый Конгрессом в 1967 г., который, «несмотря на критику содержащихся в нем отдельных ограничений, обеспечил достаточную прозрачность деятельности исполнительной власти» [18].

Кстати, аналогичный закон был принят несколько позже и в Великобритании.

В соответствии с Актом (законом) о свободе информации все лица, желающие получить 
информацию от федеральных органов власти, а также фредеральных государственных учреждений могут официально ее затребовать в форме запроса информации. В ответ на такой запрос соответствующие органы (учреждения) и их должностные лица обязаны предоставить соответствующему фризическому или юридическому лицу интересующие сведения, если они не входят в перечень видов информации, для которой установлены исключения (персональные данные, личные медицинские сведения, иные личные сведения, сведения составляющие государственную или коммерческую тайну, служебная информация о еще не принятых управленческих решениях и т.д. (§ 551 Акта)) [7].

Рассматриваемый нормативно-правовой акт обязывает официальные учреждения опубликовывать информацию о своей деятельности, а также создаваемую ими открытую информацию, имеющую значение для общества, в специальном печатном издании «Федерал реджистер». В определенной степени, это аналог «Российской газеты».

В § 551(1) Акта о свободе информации под учреждением подразумевается любое министерство, военное министерство, правительственную корпорацию, корпорацию, контролируемую правительством, или иное правительственное учреждение исполнительной власти (включая администрацию Президента), или любое независимое учреждение $[17$, c. 62].

В соответствии с рассматриваемым законом, гражданин или юридическое лицо не обязаны объяснять причины запроса на получение информации. Граждане в соответствии с рассматриваемым законом имеют право обжаловать в суд отказ учреждения в предоставлении информации. При этом истцу в случае выигрыша дела в суде могут быть возмещены судебные расходы.

Учреждение обязано предоставлять по запросам представителей документированную информацию в жесткие сроки, а также создавать условия для максимально быстрого поиска запрашиваемых документов.

Причины, по которым граждане и общественные организации запрашивают информацию у органов государственной власти, могут быть различными. Более того, можно утверждать, что через реализацию права на доступ к инфрормации граждане США могут осуществлять контроль за деятельностью органов власти. Реализация гражданами США, а также иностранцами, находящимися на территории США, права на доступ к информации активно участвовать в жизни общества, оспаривать действия и решения органов власти.

Акт о свободе информации делает исключения из правила открытости документов. Например, исключения касаются:

- национальной обороны и безопасности государства, деятельности правоохранительных органов;

- конфиденциальной личной, коммерческой или финансовой информации;

- информации, которая может позволить пользователям обойти выполнение законов;

- информации, обнародование которой прямо запрещено законом;

- документов, доступ к которым запрещен на основании решения суда;

- информации, опубликование которой может нанести ущерб;

- документы, содержащие геофизическую и геологическую информацию о нефтяных скважинах и газовых месторождениях [1].

В таких обстоятельствах учреждение имеет право не подтверждать или опровергнуть наличие у него запрашиваемых документов [15].

Орган государственной власти США вправе использовать исключение для отказа в предоставлении информации, либо его не использовать. Причем орган власти не вправе совершать такое действие в том случае, если «не в состоянии доказать нанесение вреда общественным интересам публикацией защищенных исключением документов» [1].

Нужно отметить, что этот закон применяется только к информации о деятельности исполнительной власти. Впрочем, в штатах имеется собственное законодательство, акты которого можно отнести к «законам солнечного света». Эти законы регламентируют доступ общественности к информации о деятельности органов государственной власти штатов и органов местного самоуправления.

В 2007 г. в США в развитие законодательства, регламентирующего оборот информации о деятельности органов государственной власти, был принят «Закон об открытом правительстве 2007 года» (Openness Promotes Effectiveness in our National Government Act of 2007) [19].

Эти законом были внесены изменения и дополнения в Акт о свободе информации 1967 г., в связи с тем, что он уже значительно устарел и нуждался в модернизации.

В результате Акт о свободе информации был дополнен следующими положениями:

- закон стал регулировать распространение официальной информации через электронные средства массовой информации; 
- больше стало уделяться внимания распространению официальной информации через новостные СМИ;

- появилась рекомендация по созданию при органах государственной власти подразделений по связям с общественностью, а также появилось правовое регулирование их деятельности по разрешению споров с субъектами права на доступ к офрициальной информации;

- появилось требование неукоснительного отслеживания запросов информации, время исполнения которых превышает установленные законом 10 дней;

- появилось требование об обязанности всех органов исполнительной власти ежегодно отчитываться о соблюдении и исполнении Акта о свободе информации;

- создано специальное управление (Office of Government Information Services), уполномоченное рассматривать и разрешать посредством медиации споры в отношении исполнения Акта о свободе информации, а также вести мониторинг его исполнимости в государстве и разрабатывать рекомендации по его совершенствованию;

- появилась обязанность для органов власти указывать конкретное основание для каждого редактирования или удаления текста в документах, которые попали к ним на рассмо- трение в рамках исполнения запросов на получение информации.

Таким образом, эволюция развития законодательства США о доступе к информации о деятельности органов публичной власти убедительно показывает, что необходимость предоставления населению и отдельным гражданам информации о деятельности органов публичной власти вытекает из конституционных положений, относящихся к эпохе правового становления США как государства, гарантирующих свободу слова, печати и возможность обращаться с петициями к правительству.

Соответственно, в действующих в настоящее время в США конституционных актах о доступе к информации о деятельности органов власти содержатся важные инструменты общественного контроля деятельности органов власти по принятию решений со стороны населения.

Рассмотренные выше законы США предоставляют гражданам и юридическим лицам значительные возможности по получению информации от органов государственной власти по широкому кругу вопросов, что говорит о высокой степени открытости деятельности публичной администрации, даже не смотря на оправданно установленные этим же законодательством ограничения в обнародовании той или иной информации.

\section{Литература}

1. Аналитический доклад «Прозрачность и участие: общественный контроль 2.0 в США и Европе» URL: https://echo. msk.ru/blog/potupchik/1241650-echo/ (Дата обращения: 22.04.2018).

2. Ансель М. Методологические проблемы сравнительного права // Очерки сравнительного права. М.: Прогресс, 1981. С. $36-86$.

3. Большой юридический словарь / под ред. А. Я. Сухарева, В. Д. Зорькина, В. Е. Крутских. М.: Инфра-М, 1998. 790 с.

4. Бурлай Е. В. Конституционное законодательство СССР: некоторые теоретические вопросы // Проблемы правоведения. Вып. 43. Киев: Киевский университет, 1982. С. 65-74.

5. Всеобщая декларация прав человека (принята Генеральной Ассамблеей ООН 10.12.1948) // Российская газета. 05.04.1995

6. Жидков О. Верховный Суд США: право и политика. М.: Наука, 1985. 221 с.

7. Закон США о свободе информации // Законодательство и практика средств массовой информации. 1996. Вып. 3 (19).

8. Зорькин В. Д. Россия и Конституция в XXI веке. 2-е изд., доп. М.: Норма, 2008. 592 с.

9. Козак Д. Суд в современном мире - проблемы и перспективы // Правозащитник. 2001. №3. С. 3-6.

10. Конвенция о защите прав человека и основных свобод (Заключена в г. Риме 04.11.1950) // Собрание законодательства РФ. 08.01.2001. №2.

11. Конституции зарубежных государств / сост. проф. В.В. Маклаков. 3-е изд., перераб. и доп. М.: Издательство БЕК, 2002. $340 \mathrm{c}$.

12. Косорукова Т. В. Зарубежный опыт конституционного обеспечения свободы массовой информации и права на инсормацию // Труды института государства и права Российской академии наук. 2013. №5. С. 32-44.

13. Лукьянова Е. А. Государственность и конституционное законодательство России: дисс. ... д-ра юрид. наук. М.: МГУ, 2003. 391 c.

14. Постановление Верховного Суда США от 23.07.1980 г. по делу «Richmond Newspapers, Inc. v. Virginia» // 448 U.S. $555,575$.

15. Примечания к Закону США о свободе информации // Законодательство и практика средств массовой информации. Выпуск 3 (19). Март 1996. С. 12-16.

16. Тарибо Е. В. Судебные доктрины и практика Конституционного суда Российской Федерации // Право и политика. 2005. №2. C. 118-122.

17. Трофимов М. С. Реализация права на свободу массовой информации в субъектах Российской Федерации, находящихся в пределах Южного федерального округа: дисс. ... канд. юрид. наук. Ставрополь: СГУ, 2005. 209 с. 
18. Фонд развития информационной политики URL: http://www.frip.ru/new/lib/book/jorn_russian_usa_sociolg (Дата обращения: 07.08.2017).

19. Openness Promotes Effectiveness in our National Government Act of 2007 URL: https://www.gpo.gov/fdsys/pkg/ PLAW-110publ175/pdf/PLAW-110publ175.pdf (Accessed: 26.04.2018).

\section{References}

1. Analiticheskij doklad «Prozrachnost' i uchastie: obshhestvennyj kontrol' 2.0 v SShA i Evrope» (Analytical report "Transparency and Participation: Public Control 2.0 in the US and Europe"). URL: https://echo.msk.ru/blog/potupchik/1241650echo/ (Accessed: 22.04.2018). (In Russian).

2. Ansel' M. Metodologicheskie problemy sravnitel'nogo prava (Methodological problems of comparative law) // Ocherki sravnitel'nogo prava. Moscow, 1981. P. 36-86. (In Russian).

3. Bol'shoj juridicheskij slovar' (Large legal dictionary) / ed by A.Ja. Suhareva, V.D. Zor'kina, V.E. Krutskih. Moscow, 1998. 790 p. (In Russian).

4. Burlaj E. V. Konstitucionnoe zakonodatel'stvo SSSR: nekotorye teoreticheskie voprosy (Constitutional Legislation of the USSR: Some Theoretical Questions) // Problemy pravovedenija. Issue. 43. Kiev, 1982. P. 65-74. (In Russian).

5. Vseobshhaja deklaracija prav cheloveka (prinjata General'noj Assambleej OON 10.12.1948) (Universal Declaration of Human Rights (adopted by the UN General Assembly on 10.12.1948) // Rossijskaja gazeta. 05.04.1995. No.67. (In Russian).

6. Zhidkov O. Verhovnyj Sud SShA: pravo i politika (US Supreme Court: Law and Politics). Moscow: Nauka, 1985. 221 p. (In Russian).

7. Zakon SShA o svobode informacii (The US Freedom of Information Act) // Zakonodatel'stvo i praktika sredstv massovoj informacii. 1996. Issue 3 (19). (In Russian).

8. Zor'kin V. D. Rossija i Konstitucija v XXI veke (Russia and the Constitution in the 21st century). Moscow: Norma, 2008. 592 p. (In Russian).

9. Kozak D. Sud v sovremennom mire - problemy i perspektivy (The court in the modern world - problems and prospects) /I Pravozashhitnik. 2001. No.3. P. 3-6. (In Russian).

10. Konvencija o zashhite prav cheloveka i osnovnyh svobod (Zakljuchena v g. Rime 04.11.1950) (Convention for the Protection of Human Rights and Fundamental Freedoms (concluded in Rome on 04.11.1950) // Sobranie zakonodatel'stva RF. 08.01.2001. No.2. (In Russian).

11. Konstitucii zarubezhnyh gosudarstv (Constitution of foreign states). Moscow: Izdatel'stvo BEK, 2002. 340 p. (In Russian).

12. Kosorukova T. V. Zarubezhnyj opyt konstitucionnogo obespechenija svobody massovoj informacii i prava na informaciju (Foreign experience of the constitutional guarantee of freedom of mass information and the right to information) // Trudy instituta gosudarstva i prava Rossijskoj akademii nauk. 2013. No.5. P. 32-44. (In Russian).

13. Luk'janova E. A. Gosudarstvennost' i konstitucionnoe zakonodatel'stvo Rossii (Statehood and Constitutional Legislation of Russia): thesis. Moscow, 2003. 391 p. (In Russian).

14. Postanovlenie Verhovnogo Suda SShA ot 23.07.1980 g. po delu «Richmond Newspapers, Inc. v. Virginia» (The US Supreme Court ruling of July 23, 1980 on the case of Richmond Newspapers, Inc. vs Virginia ») // 448 U.S. 555, 575. (In Russian).

15. Primechanija k Zakonu SShA o svobode informacii (Notes to the US Freedom of Information Act) // Zakonodatel'stvo i praktika sredstv massovoj informacii. Issue 3 (19). 1996. March. P. 12-16. (In Russian).

16. Taribo E. V. Sudebnye doktriny i praktika Konstitucionnogo suda Rossijskoj Federacii (Judicial Doctrines and Practice of the Constitutional Court of the Russian Federation) // Pravo i politika. 2005. No.2. P. 118-122. (In Russian).

17. Trofimov M. S. Realizacija prava na svobodu massovoj informacii v sub\#ektah Rossijskoj Federacii, nahodjashhihsja v predelah Juzhnogo federal'nogo okruga (Realization of the right to freedom of mass information in the constituent entities of the Russian Federation located within the Southern Federal District): thesis. Stavropol', 2005. 209 p. (In Russian).

18. Fond razvitija informacionnoj politiki (Information Policy Development Fund) // http://www.frip.ru/new/lib/book/jorn russian_usa_sociolg (Accessed: 07.08.2017) (In Russian).

19. Openness Promotes Effectiveness in our National Government Act of 2007 URL: https://www.gpo.gov/fdsys/pkg/ PLAW-110publ175/pdf/PLAW-110publ175.pdf (Accessed: 26.04.2018). 